\title{
KARAKTER KADITA DALAM MOBILE LEGENDS BANG-BANG: KAJIAN ETNOGRAFI VISUAL
}

\author{
Yuni Zaharani*1, Pandu Pramudita ${ }^{2}$, Puri Kurniasih ${ }^{3}$, Gatot Sukendro ${ }^{4}$ \\ Program Studi Desain Komunikasi Visual, Universitas Indraprasta PGRI \\ *corresponding author: Yuni Zaharani, yunizazaharani@gmail.com, Jakarta, Indonesia
}

\begin{abstract}
Abstrak. Nyi Roro Kidul merupakan mitologi yang tersebar di daerah pesisir pantai selatan pulau Jawa. Moonton mengadaptasi figur ini menjadi konsep visual sebagai karakter permainan online berbasis android, yaitu Mobile Legends Bang-bang pada hero Kadita dengan role sebagai mage. Karakter mitologi ini muncul sebagai daya tarik tersendiri dalam era digital. Penelitian ini bertujuan untuk menganalisis karakter Nyi Roro Kidul yang divisualisasikan pada hero Kadita. Banyak karakter-karakter yang digunakan dalam video permainan diciptakan secara imajinatif dan tidak memiliki kedekatan secara sosial-budaya dengan pemain-pemain asal Indonesia. Studi ini akan menunjukkan hasil adaptasi dari karakter visual Nyi Roro Kidul ke dalam hero Kadita. Etnografi visual menjadi metode yang memberi pengalaman kebudayaan Jawa tentang konsep visualisasi Nyi Roro Kidul. Untuk menganalisis perubahan media dan transformasi bentuk visual Nyi Roro Kidul dalam hero Kadita digunakan teori adaptasi. Penelitiani ini mendapatkan hasil bahwa terdapat adaptasi karakter Nyi Roro Kidul pada hero Kadita dalam permainan tersebut. Analisis ini diharapkan menstimuli akademisi desain komunikasi visual untuk merancang karakter-karakter tokoh digital berdasarkan atas folklor yang terdapat di Indonesia.
\end{abstract}

Kata Kunci: Adaptasi, Etnografi Visual, Kadita, Mobile Permainan, Nyi Roro Kidul

\begin{abstract}
Nyi Roro Kidul is a mythological figure revered in the southern coast of Java Island. Moonton, a permainan developer of android based permainan Mobile Legends Bang-bang, adapted this figure into a visual concept of one of its in-permainan character with a role of mage, namely the hero Kadita. The inclusion of Javanese mythological figure has its own charm in the growing digital era. This is because many of the characters found in video permainans are created imaginatively and generally do not have any relation in a socio-cultural sense with Indonesian players. This study aims to analyze the character of Nyi Roro Kidul which was adapted and visualized into the hero Kadita in Mobile Legends Bang-bang using visual ethnography method to infer the Javanese cultural experience on the concept and visualization of this in-permainan character. The adaptation theory was used to analyze the changes and visual transformation related to the media changes from Nyi Roro Kidul as a mythological figure to the hero Kadita as an in-permainan character. This study found that Kadita's character was the result of adaptation representing a mixture between the image of Javanese Nyi Roro Kidul an an influence of European culture. However, the dominance given by the image of Nyi Roro Kidul as a part of visual culture makes Kadita recognized as a character from Indonesia. The implication of this study is to stimulate visual communication design academics in adapting the rich Indonesian folklors as an underlying concept in designing characters and figures for interactive digital media.
\end{abstract}

Keywords : Adaptation, Visual Ethnography, Kadita, Mobile Permainan, Nyi Roro Kidul 


\section{Pendahuluan}

Indonesia memiliki beragam folklor yang tersebar di daerah-daerah. Folklor adalah sebagian kebudayaan suatu kolektif, yang tersebar dan diwariskan secara turun-temurun, di antara kolektif macam apa saja, secara tradisional dalam versi yang berbeda, baik dalam bentuk lisan maupun contoh yang disertai dengan gerak isyarat atau alat pembantu pengingat (Endraswara 2013, 2). Folklor dapat dikaitkan dengan cerita rakyat yang dituturkan secara lisan dan biasanya bersifat turun temurun serta tidak dituliskan (IIminisa, Siswanto, and Basthomi 2016, 997). Folklor merupakan salah satu wujud kebudayaan berupa ide atau gagasan. Sebagai sebuah ide atau gagasan, folklor terletak di kepala dan pemikiran masyarakat. Folklor memuat nilai sosial budaya dan kearifan lokal khas daerah yang patut dijaga.

Banyak dari folklor-folklor tersebut berakhir sebagai kumpulan cerita pengantar tidur anak yang memiliki nilai sosial dan kearifan lokal, seperti Sangkuriang, Baru Klinting, Lutung Kasarung, Malin Kundang dan lain sebagainya. Namun tidak sedikit pula, di antara folklor-folklor tersebut adalah mitologi yang diyakini pernah ada atau bahkan diyakini masih ada hingga sekarang meski dalam bentuk gaib, seperti Prabu Siliwangi, Jaka Tarub, Nyai Bagelen, Calon Arang dan lain sebagainya. Salah satu yang melegenda di tanah Jawa adalah Nyi Roro Kidul. Nyi Roro Kidul dikenal dengan beberapa nama yang mengidentitaskan sosoknya, sepeti Kanjeng Roro Kidul, Ratu Pantai laut Selatan, dan Kadita.

Seiring perkembangan zaman, masyarakat Indonesia berusaha untuk memanfaatkan teknologi untuk melestarikan kebudayaan yang telah dibangun oleh nenek moyang mereka, salah satunya melalui media digital. Hal ini seperti diungkapkan oleh Andrew Strathern dan Pamela J. Stewart, bahwa solusi untuk mempublikasi kumpulan material kebudayaan yang memiliki berbagai macam jenis adalah dengan cara merekam dalam media digital ( $\underline{\text { Strathern and }}$ Stewart 2008, 73). Penggunaan teknologi ini, selain berusaha menyimpan budaya dalam bentuk virtual juga memungkinkan desainer untuk memberikan sentuhan kreatif yang dapat menarik generasi muda.

Permainan menjadi salah satu media digital yang dapat dimanfaatkan untuk melestarikan kebudayaan, termasuk folklor. Permainan diciptakan dengan tujuan menghibur para pemainnya (Brathwaite and Schreiber 2009). Sedangkan permainan online adalah permainan yang terdiri dari mesin-mesin yang saling terhubung dengan jaringan yang dapat dimainkan, diakses oleh banyak orang (Adams 2013). Permainan telah banyak berevolusi, mulai dari permainan tradisional sampai permainan digital yang memiliki beragam jenis, seperti permainan monopoly pada papan permainan, permainan pong pada permainan arcade, permainan nintendo pada permainan konsol, permainan counter strike pada permainan komputer, permainan warcraft III pada permainan online. Dari masing-masing jenis permainan tersebut ada yang memiliki banyak pemain yang dapat menandakan permainan tersebut sudah bagus dan memiliki sedikit pemain yang dapat menandakan permainan tersebut buruk (Yogatama, Kharisma, and Fanani 2019, 2559).

Desainer yang turut berusaha menyimpan material kebudayaan dalam bentuk kreatif memiliki sudut pandang yang berbeda dengan para humanis dalam memperlakukan material kebudayaan. Seperti yang dilakukan oleh Moonton, sebuah perusahaan yang bergerak dalam permainan seluler. Salah satu produk permainan seluler dari perusahaan ini adalah Mobile Legends Bang-bang. Mobile legend bang-bang menjadi salah satu permainan seluler dengan jutaan pemain di dunia. Terbukti dari sebuah market aplikasi play store dengan jumlah unduhan pada bulan maret 2018 mencapai lebih dari 100 juta, berarti 100 juta lebih perangkat smartphone telah menginstal permainan ini sejak peluncuran global untuk platform android pada 11 Juli 2016. Sedangkan pada laman Mobile Legends Indonesia di sebuah media sosial 
facebook pada bulan september 2018 mencapai 10,8 juta orang yang mengikuti dan 10,4 juta orang yang menyukai laman tersebut (Yogatama, Kharisma, and Fanani 2019, 2559).

Banyak karakter-karakter "hero" yang diciptakan oleh Moonton mengadaptasi dari folklor-folklor yang berkembang di dunia, termasuk dari Indonesia, yaitu Gatotkaca dan Kadita. Penelitian terdahulu (Pramudita 2018) secara khusus mengkaji karakter Gatotkaca dalam mobile legends bang-bang. Berbeda dengan penelitian ini yang berfokus pada analisis karakter Kadita dalam permainan mobile legend bang-bang dengan menggunakan lukisan karya Basuki Abdullah, 'Nyi Roro Kidul' karya Basuki Bawono, dan 'Queen of Ocean' karya Iyan Riyana sebagai rujukan analisis, Pandu Pramudita lebih berfokus pada retaknya dualitas struktur wayang dalam karakter Gatotkaca pada permainan mobile legend bang-bang.

Karakter Gatotkaca dirilis pada tahun 2017, merupakan hasil adaptasi dari karakter Gatotkaca dalam komik 'Garudayana' yang diciptakan oleh Is Yuniarto. Karakter Mobile legend bang-bang lainnya yang mengadaptasi folklor dari Indonesia adalah Kadita. Moonton mengadaptasi tokoh ini dari mitologi Jawa yaitu Nyi Roro Kidul.

Moonton mengadaptasi hero yang terinspirasi dari folklor yang ada di Indonesia untuk memberikan apresiasi atas antusiasme permainan mobile legend bang-bang Indonesia. Indonesia merupakan salah satu negara dengan pengguna mobile legend bang-bang terbanyak di dunia. Permainan mobile legend bang-bang telah diunduh sebanyak 35 juta kali dan ada 8 juta pengguna aktif harian di Indonesia pada tahun 2017. Terdapat 43 juta pengguna aktif bulanan di Asia Tenggara, Indonesia hampir melebihi 50 persen dari jumlah keseluruhan pengguna Asia Tenggara tersebut (Yogatama, Kharisma, and Fanani 2019, 2559). Dengan demikian tidaklah berlebihan Montoon menghadirkan hero yang berasal dari folklor Indonesia karena Indonesia merupakan salah satu pasar terbesarnya.

Seperti halnya nama Gatotkaca yang mengambil nama wayang Gatotkaca, nama karakter Kadita juga mengambil nama lain dari Nyi Roro Kidul yang konon adalah nama sebelum menjadi penguasa Laut Selatan, yaitu Kadita. Dengan nama karakter Kadita, dan nama kedua 'Ocean Goddes' yang identik dengan sebutan Ratu Pantai Laut Selatan, karakter ini memainkan role sebagai mage. Role mage adalah role mobile legend yang sangat penting dalam tim, karena hero seperti ini menjadi sumber damage yang dapat memberikan damage magical pada musuh. Role mage memiliki kekuatan dan subrole nya masing-masing. Menurut Coogan (2006, 31-39) kekuatan super merupakan elemen yang paling mudah untuk dikenali dari seorang superhero. Setiap karakter dibuat untuk menjadi yang terkuat.

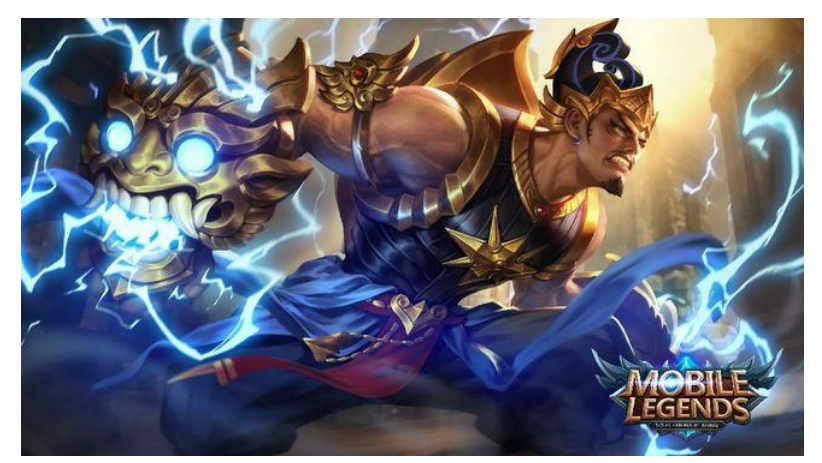

Gambar 1 Karakter Gatotkaca dalam Mobile Legend: Bang-bang Sumber: https://akcdn.detik.net.id, 2017

Karakter Gatotkaca yang pada awalnya adalah karakter yang diciptakan dalam bentuk cerita dan menjelma sebagai boneka yang dimainkan oleh subjek yang disebut dengan dalang. Dan hal tersebut masih bertahan sampai sekarang. Sosok Gatotkaca tidak keluar dari sebuah karakter boneka atau bahkan selalu berada dalam alur yang jalan ceritanya dapat dimainkan 
oleh si penciptanya. Meskipun demikian, menurut Pramudita (2018) telah terjadi keretakan struktur budaya pada karakter Gatotkaca dalam Mobile Legends Bang-bang, yaitu menghilangkan unsur agen, yaitu sang dalang atau pengatur jalan cerita Adapun karakter Kadita diadaptasi dari makhluk mitologi masyarakat Indonesia, khususnya di masyarakat pesisir selatan Jawa, yaitu Nyi Roro Kidul yang diyakini keberadaannya dan tidak jarang masyarakat pesisir pantai laut selatan ini melakukan ritual untuk memujanya atau hanya sekedar menghormatinya.

Lalu, bagaimana Moonton memvisualisasikan Nyi Roro Kidul pada karakter Kandita yang diadaptasi dari kebudayaan Jawa? Dan, bagaimana prospek penciptaan karakter permainan video yang mengadaptasi folklor Indonesia bagi pemain video permainan di Indonesia? Dalam hal ini, penulis berusaha untuk menganalisis karakter Nyi Roro Kidul yang divisualisasikan pada karakter Kadita dalam permainan seluler Mobile Legends Bang-bang dengan menggunakan teori adaptasi. Untuk melihat ciri adaptasi yang digunakan dalam sebuah budaya, menurut Alland perlu pemahaman sitem kognisi dan kebiasaan manusia sebagai struktur respon aturan mereka sendiri dan berkembang dalam konteks konsistensi internal (Alexander Alland 1975, 69).

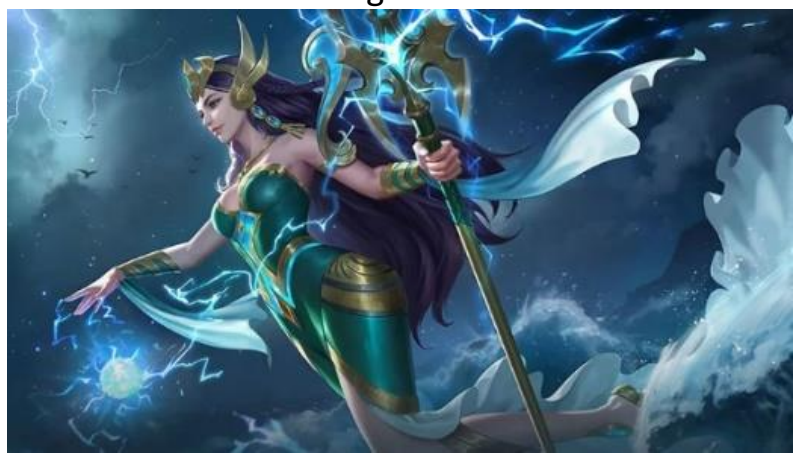

Gambar 2 Karakter Kadita dalam Mobile Legends Bang-bang Sumber: esport.id, 2018

\section{Metode}

Metode yang digunakan dalam penelitian ini adalah etnografi visual. Etnografi visual menjadi metode yang memberi pengalaman kebudayaan Jawa tentang konsep visualisasi Nyi Roro Kidul. Menurut Jane Jackson, etnografi adalah metode penelitian sosial yang memberikan pemahaman makna mengenai praktik kebudayaan atau perilaku dan kepercayaan pada kelompok atau orang-orang tertentu dalam waktu dan konteks khusus (Jackson 2015, 240). Adapun mengenai etnografi visual, Jackson menjelaskan bahwa etnografi visual memungkinkan penelitinya mengumpulkan dan menganalisis data-data yang sebagian besar adalah data visual termasuk dalam bentuk gambar digital (Jackson 2015, 243). Adapun menurut Terence Wright, untuk melihat simbol visual dalam sebuah budaya kontemporer maka perlu adanya ketepatan budaya visual dan representasi visual dalam melihat sebuah objek kebudayaan (Kockel, Craith, and Frykman 2012).

Dalam penelitian ini, peneliti akan mengambil data-data visual berkaitan dengan Nyi Roro Kidul untuk menganalisis budaya visual dan representasi Nyi Roro Kidul yang diadaptasi pada karakter Kadita dalam Mobile Legends Bang-bang. Data-data visual tersebut peneliti ambil dari sumber internet dengan asumsi bahwa media internet menyediakan ruang ekspresi masyarakat dalam mempublikasi karya, dalam hal ini representasi Nyi Roro Kidul dalam bentuk gambar digital yang dapat diakses tanpa memerlukan kemampuan khusus, seperti sihir. Selain itu, peneliti juga menggunakan metode kuesioner dengan memanfaatkan media internet, yaitu google form untuk menggali informasi dari bawah. 


\section{Hasil dan Pembahasan}

\section{Mitos Nyi Roro Kidul yang Berkembang di Pulau Jawa}

Di wilayah Sunda, banyak cerita yang mengkisahkan asal mula munculnya Nyi Roro Kidul. Robert Wessing menuliskan Nyi Roro Kidul adalah seorang putri Kerajaan Pajajaran. Dia menuliskan versi lain bahwa Nyi Roro Kidul juga diklaim berasal dari Kerajaan Galuh, kedua ceritanya bermuara ke laut selatan (Wessing 1997). Nyi Roro Kidul juga sangat erat dengan sejarah Kerajaan Mataram yang memiliki peran penting dalam mengukuhkan Raja Jawa. Dalam Babad Tanah Jawi, Olthof menuliskan bahwa terdapat hubungan antara Nyi Roro Kidul dengan Raja Jawa sebagai sepasang suami istri meskipun berakhir pada Paku Buwono X yang hubungan itu berakhir ketika Nyi Roro Kidul hanya mengakuinya sebagai anak (Budiningtyas et al. 2018, 2108). Namun ketika terjadi perpecahan kerajaan karena adanya Perjanjian Giyanti, Panembahan Senopati mendirikan Kerajaan Mataram Islam di Yogyakarta. Sebagaimana mitos yang mengakar di masyarakat Jawa, Nyi Roro Kidul kemudian menjadi istri gaib dari Panembahan Senopati (Budiningtyas et al. 2018, 2109). Hal ini sedikit kontradiktif, ketika Panembahan Senopati mendirikan kerajaan dengan dasar Islam sedang Nyi Roro Kidul adalah makhluk animisme. Hal ini terlihat sebagai hegemoni budaya jawa (Pambudi 2018, 50-51).

Mitos Nyi Roro Kidul banyak dimuat dalam berbagai bentuk, diantaranya cerita dongeng, sejarah, film, maupun lukisan yang dijadikan rujukan penelitian ini yaitu lukisan 'Nyi Roro Kidul' karya Basuki Abdullah, 'Nyi Roro Kidul' karya Basuki Bawono, dan 'Queen of Ocean' karya Iyan Riyana.

\section{Representasi Visual Nyi Roro Kidul dan Karakter Kadita}

Nyi Roro Kidul diyakini adalah sosok gaib yang intangible (Budiningtyas et al. 2018, 2102). Dengan kata lain, dia adalah sosok yang tidak dapat diindera. Oleh sebab itu, dibutuhkan media pendukung yang dapat merepresentasikan karakter Nyi Roro Kidul secara visual. Dalam hal ini, media yang paling umum menjadi rujukan mengenai sosok Nyi Roro Kidul adalah lukisan.

Peneliti mengambil 3 sampel lukisan Nyi Roro Kidul sebagai representasi visual Nyi Roro Kidul yang memiliki keterangan pelukis yang diambil dari media internet. 3 lukisan tersebut antara lain lukisan 'Nyi Roro Kidul' karya Basuki Abdullah, 'Nyi Roro Kidul' karya Basuki Bawono, dan 'Queen of Ocean' karya Iyan Riyana. Karakter Kadita yang akan diidentivikasi secara visual adalah dalam bentuk animasi yang berposisi sebagai budaya visual Nyi Roro Kidul. Untuk menganalisis konsistensi visualisasi Nyi Roro Kidul dalam karakter Kadita sebagai pembuktian adaptasi yang dilakukan oleh Moonton maka peneliti membuat table sebagai berikut.

Tabel 1 Analisis Adaptasi Visual Nyi Roro Kidul dalam Karakter Kadita

\begin{tabular}{ccccc}
\hline $\begin{array}{c}\text { Ciri } \\
\text { Visual }\end{array}$ & Representasi Visual & Budaya Visual \\
\hline Karya & $\begin{array}{c}\text { 'Nyi Roro Kidul' } \\
\text { karya Basuki } \\
\text { Abdullah }\end{array}$ & $\begin{array}{c}\text { 'Nyi Roro Kidul' } \\
\text { karya Basuki } \\
\text { Bawono }\end{array}$ & $\begin{array}{c}\text { 'Queen of Ocean' } \\
\text { karya lyan Riyana }\end{array}$ & $\begin{array}{c}\text { Kadita - Ocean } \\
\text { Goddes }\end{array}$ \\
\cline { 2 - 5 } & & &
\end{tabular}




\begin{tabular}{|c|c|c|c|c|}
\hline $\begin{array}{c}\text { Ciri } \\
\text { Visual }\end{array}$ & & Representasi Visu & & Budaya Visual \\
\hline Ciri Fisik & $\begin{array}{l}\text {-Wanita } \\
\text {-Rambut } \\
\text { panjang } \\
\text { terurai } \\
\text {-Kulit sawo } \\
\text { matang } \\
\text {-Tubuh } \\
\text { semampai }\end{array}$ & $\begin{array}{l}\text {-Wanita } \\
\text {-Rambut panjang } \\
\text { terurai dengan } \\
\text { sedikit gelungan } \\
\text { di bagian atas } \\
\text {-Tubuh } \\
\text { semampai } \\
\text {-Kulit sawo } \\
\text { matang }\end{array}$ & $\begin{array}{l}\text {-Wanita } \\
\text {-Rambut panjang } \\
\text { dikepang dan } \\
\text { terdpat gelungan } \\
\text { di bagian atas } \\
\text {-Tubuh semampai } \\
\text {-Kulit sawo } \\
\text { matang }\end{array}$ & $\begin{array}{l}\text {-Wanita } \\
\text {-Rambut panjang } \\
\text { terurai } \\
\text {-Kulit putih } \\
\text {-Tubuh semampai }\end{array}$ \\
\hline Busana & $\begin{array}{l}\text {-Pakaian } \\
\text { kemban Jawa } \\
\text {-Warna pakaian } \\
\text { biru kehijauan }\end{array}$ & $\begin{array}{l}\text {-Pakaian kemban } \\
\text { Jawa } \\
\text {-Warna pakaian } \\
\text { hijau }\end{array}$ & $\begin{array}{lr}\text {-Pakaian kemban } & \text { dengan } \\
\text { Jawa jarit } \\
\text { bawahan } \\
\text { motif 'semen' } \\
\text {-Warna pakaian } \\
\text { dominan hijau } \\
\text { dengan batik } \\
\text { cokelat }\end{array}$ & $\begin{array}{l}\text {-Pakaian kemben } \\
\text { Jawa } \\
\text {-Warna dominan } \\
\text { hijau }\end{array}$ \\
\hline Aksesoris & -Kalung & $\begin{array}{l}\text {-Mahkota } \\
\text {-Sanggul } \\
\text {-Anting-anting } \\
\text {-Kalung } \\
\text {-Kelat bahu } \\
\text {-Gelang } \\
\text {-Sabuk }\end{array}$ & $\begin{array}{l}\text {-Mahkota } \\
\text {-Sanggul } \\
\text {-Anting-anting } \\
\text {-Kalung } \\
\text {-Gelang } \\
\text {-Sabuk } \\
\text {-Selendang }\end{array}$ & $\begin{array}{l}\text {-Mahkota } \\
\text {-Sumping } \\
\text {-Anting-anting } \\
\text { - Kalung } \\
\text {-Kelat bahu } \\
\text {-Gelang } \\
\text {-Senjata trisula }\end{array}$ \\
\hline
\end{tabular}

Sumber: Data diolah, 2019

Berdasarkan tabel di atas, secara umum Nyi Roro Kidul divisualisasikan dalam sosok wanita berambut panjang. Busana yang dikenakan merupakan kemben, pakaian khas wanita kerajaan, terutama di wilayah Jawa. Adapaun perhiasan yang dikenakan Nyi Roro Kidul yang cenderung konsisten adalah mahkota, kalung, gelang, dan sabuk. Hal ini seperti yang dikatakan oleh Wright dimana budaya visual tersebut merepresentasikan budaya yang digunakan oleh masyarakat setempat (Kockel, Craith, and Frykman 2012), dalam hal ini adalah masyarakat Jawa.

Meskipun demikian, terjadi adaptasi visual berbeda pada karakter Kadita yang tidak terdapat pada karakter Nyi Roro Kidul yang tervisualisasi dalam lukisan-lukisan 'Nyi Roro Kidul' yaitu pada ciri fisik yang berkulit putih dan aksesoris dengan menggunakan senjata trisula.

Pada penggunaan senjata trisula, hal ini mengingatkan pada mitologi-mitologi barat yang melibatkan trisula sebagai senjata utama dewa-dewa penguasa laut seperti Dewa Neptunus dari mitologi Romawi dan Dewa Poseidon dari Mitologi Yunani. Adaptasi ini memperkuat posisi karakter Kadita sebagai karakter yang menguasai laut. Senjata yang sama juga digunakan oleh Aquaman, salah satu karakter DC Comics, karakter pahlawan super yang memiliki kekuatan dan kekuasaan di laut.

Ciri fisik yang berkulit putih dan aksesoris senjata trisula menunjukkan adanya proses akulturasi pada adaptasi visual karakter Kadita dalam mobile legend bang-bang. Kulit sawo matang Nyi Roro Kidul yang ada pada ketiga lukisan rujukan menjadi identitas khas kulit orang Jawa, berbeda dengan kulit putih Kadita dalam mobile legend yang lebih merepresentasikan orang Eropa atau ras Kaukasoid. Aksesoris yang digunakan Nyi Roro Kidul pada 3 lukisan rujukan juga merepresentasikan budaya Jawa, sedangkan aksesoris senjata trisula pada Kadita dalam 
mobile legend lebih merepresentasikan budaya Barat. Akulturasi sendiri menurut SRC (Lakey $2003,104)$ didefinisikan sebagai perubahan budaya yang dimulai dengan dua atau lebih sistem budaya yang independen. Dinamikanya dapat dilihat sebagai proses adaptasi selektif terhadap nilai sistem-sistem, proses dari integrasi dan perbedaan, generasi dari perkembangan secara terus menerus dan operasi dari penentuan peran dan faktor-faktor kepribadian.

Sebuah budaya baru harus melakukan adaptasi dan mengalami proses perubahan dan penyesuaian secara kontinyu sehingga akhirnya bisa diterima oleh masyarakat. Nyi Roro kidul bukanlah budaya baru, namun karakter Kadita dalam mobile legend bang-bang merupakan suatu kebaruan. Kadita dalam mobile legend telah mengalami adaptasi visual dengan tampilan yang lebih kekinian dan modern agar dapat diterima oleh masyarakat, khususnya para pengguna mobile legend.

\section{Prospek Karakter Folklor dalam Video Permainan}

Peneliti mensurvei dari 100 pengguna (pemain) Mobile Legends Bang-bang secara acak tanpa membatasi umur. Dari 100 responden, terdapat $87,7 \%$ yang pernah menggunakan 'hero' Kadita, sedang lainnya mengaku belum pernah menggunakan hero ini. Dari $87,7 \%$ tersebut, hanya $13,3 \%$ adalah pengguna sedang lainnya bersifat kadang-kadang. Dari para pengguna hero tersebut dapat dipastikan bahwa mereka adalah pengguna tipe role mage. Pengguna yang kadang-kadang menggunakan Kadita 16\% karena Kadita hero asli Indonesia, 26\% mencoba kemampuan Kadita, 23\% menggunakan sesuai role, dan yang paling besar, $36 \%$ hanya mencobacoba. Sedangkan mereka yang belum pernah mencoba 'hero' Kadita, $29 \%$ memang belum membeli karakter tersebut, $71 \%$ tidak sesuai dengan role yang biasa mereka mainkan, dan tidak ada yang menjawab tidak tertarik.

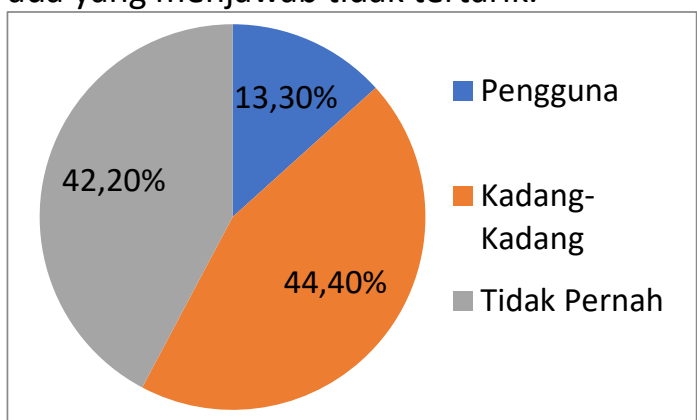

Gambar 3 Popularitas 'Hero' Kadita di kalangan Pemain Mobile Legends Bang-bang Indonesia Sumber: data diolah, 2019

Fitur 'leaderboard' Mobile Legens Bang-bang berdasarkan 'hero' yang diakses pada tangga 22 Juni 2019, dari 10 Top Global Kadita, hanya terdapat 2 pemain yang berbendera Indonesia, dan itupun menduduki peringkat $2^{\text {nd }}$ dan $4^{\text {th }}$. Sedang peringkat $1^{\text {st }}$ dicapai oleh pemain berbendera Philippines. Hal serupa juga terjadi pada 'hero' Gatotkaca, dimana dari 10 Top Global Gatotkaca, hanya terdapat 2 pemain berbendera Indonesia yang menduduki peringkat $7^{\text {th }}$ dan $10^{\text {th }}$ sedang peringkat $1^{\text {st }}$ dicapai oleh pemain berbendera India. Hal ini menandakan bahwa, karakter Kadita yang terinspirasi dari mitologi Nyi Roro Kidul mampu dinikmati oleh penduduk dunia dan sebagian dari pemain Indonesia dengan trampil menguasai karakter ini meski tidak berada pada peringkat pertama.

\section{Simpulan}

Karakter Kadita yang dirilis oleh Moonton dalam permainan Mobile Legends Bang-bang secara etnografi visual diadaptasi dari tokoh mitologi Jawa yaitu Nyi Roro Kidul. Hal ini 
dibuktikan adanya konsistensi yang muncul di dalam karakter Kadita yang menjadi budaya visual atas Nyi Roro Kidul. Adapun sebagai representasi visual atas Nyi Roro Kidul telah didapatkan dari lukisan Nyi Roro Kidul. Pada dasarnya, kehadiran karakter Kadita maupun Gatotkaca dalam permainan ini sangat disambut antusias oleh para permainan Mobile Legends Bang-bang Indoensia. Namun, penggunaan karakter bukan berdasar atas suka atau tidak suka terhadap karakter melainkan kemampuan pemain sendiri dalam menggunakan karakter. Sehingga, dalam hal ini desainer Indonesia memiliki peluang kembali untuk memberikan inspirasi karakter lokal pada role lainnya. Terakhir, analisis ini diharapkan menstimuli akademisi desain, khususnya desain komunikasi visual, untuk merancang karakter visual berdasarkan atas folklor yang terdapat di Indonesia.

\section{Daftar Pustaka}

Adams, Ernest. 2013. Fundamentals of Game Design. 3rd ed.: Pearson Education.

Alexander Alland, Jr. 1975. "Adaptation." Annual Review of Anthropology 4 (1): 59-73. https://doi.org/10.1146/annurev.an.04.100175.000423.

Brathwaite, Brenda, and lan Schreiber. 2009. Challenges for game designers. Nelson Education.

Budiningtyas, Raden Rara Erna Sadiarti, Heddy Shri Ahimsa-Putra, Janianton Damanik, and Sumijati Atmosudiro. 2018. "Myth of the Queen of the South Sea and Kasunanan Palace as a Tourism Attraction of Baluwarti, Surakarta." International Journal of Pure and Applied Mathematics 119 (15): 2101-2112. https://acadpubl.eu/hub/2018-11915/4/620.pdf.

Coogan, Peter MacFarland. 2006. Superhero: The secret origin of a genre. MonkeyBrain.

Endraswara, Suwardi. 2013. Folklor Nusantara: Hakikat, Bentuk, dan Fungsi. Yogyakarta: Ombak.

Ilminisa, Ranggi Ramadhani, Wahyudi Siswanto, and Yazid Basthomi. 2016. "Bentuk karakter anak melalui dokumentasi folklor lisan kebudayaan lokal." Jurnal Pendidikan: Teori, $\begin{array}{lllll}\text { Penelitian, dan Pengembangan } 1 & \text { 996-1001. }\end{array}$ http://journal.um.ac.id/index.php/iptpp/article/view/6353.

Jackson, Jane. 2015. "Ethnography." In Research Methods in Intercultural Communication, edited by Zhu Hua, 239-254.

Kockel, Ullrich, Máiréad Nic Craith, and Jonas Frykman. 2012. "Introduction: The Frontiers of Europe and European Ethnology." In A Companion to the Anthropology of Europe, edited by Ullrich Kockel, Máiréad Nic Craith and Jonas Frykman, 1-10. Malden, USA: John Wiley \& Sons, Inc.

Lakey, Paul N. 2003. "Acculturation: A review of the literature." Intercultural communication studies 12 (2): 103-118. 
Pambudi, Buyung. 2018. "Hegemoni Dalam Mitos Nyai Roro Kidul Dalam Novel Sang Nyai 1 Karya Budi Sardjono." Prosiding Seminar Sastra Tema: Resonansi Kata, Graha STKIP PGRI Bangkalan.

Pramudita, Pandu. 2018. "Retaknya Dualitas Struktur Wayang Dalam Karakter Gatotkaca Pada Permainan Dalam-Jaringan Mobile Legends: Bang Bang." Prosiding Seminar Dosen Hasil Penelitian Dan Pengabdian Kepada Masyarakat Tahun 2018, Gedung 7, Kampus B, Universitas Indraprasta PGRI.

Strathern, Andrew, and Pamela J. Stewart. 2008. "Multimedia Ethnography and Digitalization of Archives: A Synergistic Project." Journal of Ritual Studies 22 (1): 73-76. http://www.jstor.org/stable/44368784.

Wessing, Robert. 1997. "A Princess from Sunda: Some Aspects of Nyai Roro Kidul." Asian Folklore Studies 56 (2): 317-353. https://doi.org/10.2307/1178730.

Yogatama, I Ketut Sidharta, Agi Putra Kharisma, and Lutfi Fanani. 2019. "Analisis Faktor-Faktor Yang Memengaruhi Minat Pemain Dalam Permainan MOBA (Studi Kasus: Mobile Legends: Bang-Bang!)." Jurnal Pengembangan Teknologi Informasi dan Ilmu Komputer 3 (3): 2558-2566. http://j-ptiik.ub.ac.id/index.php/j-ptiik/article/view/4742. 